\title{
Predictors of Symptom Burden in Patients with COPD on LAMA Monotherapy: Multivariable Analysis of a Claims-Linked Survey Study
}

\author{
Beth Hahn (D) - Richard H. Stanford - Alyssa Goolsby Hunter • \\ John White · Breanna Essoi · Riju Ray
}

Received: May 16, 2019 / Published online: August 7, 2019

(C) The Author(s) 2019

\begin{abstract}
Introduction: Many patients with chronic obstructive pulmonary disease (COPD) prescribed long-acting muscarinic antagonist (LAMA) monotherapy remain symptomatic. This multivariable analysis of a previously reported claims-linked, cross-sectional survey assessed symptom burden measured by the COPD assessment test (CAT) in patients treated with LAMA monotherapy.

Methods: Eligible patients aged $\geq 40$ years with COPD ( $\geq 2$ International Classification of Diseases-10th Revision-Clinical Modification [ICD-
\end{abstract}

Enhanced Digital Features To view enhanced digital features for this article go to https://doi.org/10.6084/ m9.figshare.8948918.

Electronic supplementary material The online version of this article (https://doi.org/10.1007/s41030019-00098-1) contains supplementary material, which is available to authorized users.

B. Hahn $(\bowtie) \cdot$ R. H. Stanford

US Value Evidence and Outcomes, GSK, 5 Moore Drive, Research Triangle Park, NC 27709-3398, USA e-mail: beth.a.hahn@gsk.com

A. G. Hunter · J. White - B. Essoi

Health Economics and Outcomes Research, Optum Life Sciences, 11000 Optum Circle, Eden Prairie, MN 55344, USA

R. Ray

US Medical Affairs, GSK, 5 Moore Drive, Research

Triangle Park, NC 27709-3398, USA
10-CM] diagnosis codes $\geq 30$ days apart during the 12 -month baseline period) and $\geq 2$ claims for LAMA monotherapy in the latter half of the baseline period were identified using claims data from the Optum Research Database. Patients completed a survey and 7-day daily diary; baseline clinical characteristics and resource utilization were assessed from claims data. Association between symptom burden and baseline characteristics was assessed using generalized linear regression modeling with normal distribution and identity link.

Results: Overall, 433 patients prescribed LAMA monotherapy with claims-linked survey and diary data were included in the analysis. Most patients $(85.5 \%)$ had a mean CAT score $\geq 10$; $39.0 \%$ had scores $\geq 21$. Overall, the factors most related to a clinically meaningful increase in CAT score ( $\geq 2$ points) were being diagnosed with COPD for $>5$ years and being a current smoker (2.25 points, $P=0.003$ and 2.22 points, $P=0.025$, respectively).

Conclusions: Results demonstrate that many patients with COPD receiving LAMA monotherapy remain symptomatic, especially those diagnosed $>5$ years ago or those who continue to smoke. Use of patient-reported outcomes such as the CAT should be considered part of routine visits for patients with COPD.

Funding: GlaxoSmithKline (GSK study number 205862 [HO-16-16642]). 
Keywords: Bronchodilator agents; COPD; Long-acting muscarinic antagonists; Multivariable analysis; Patient-reported outcome measures

\section{INTRODUCTION}

Chronic obstructive pulmonary disease (COPD) is one of the most common chronic diseases, and is a leading cause of morbidity and mortality worldwide [1]. In the United States, it is estimated to affect 15.7 million individuals and is the third leading cause of death [2]. It has a high clinical and economic burden, is a leading cause of hospitalization and emergency department (ED) visits and contributes significantly to both direct and indirect healthcare costs $[1,3]$. The most common symptoms experienced by patients with COPD include dyspnea, coughing, sputum production, wheezing, chest tightness, and chest congestion [4]. Symptom burden differs depending on the patient population and disease severity [4]; however, most individuals perceive it as a significant ongoing challenge in their day-to-day activities [5]. Bronchodilation with a long-acting muscarinic antagonist (LAMA), a long-acting $\beta_{2}$-agonist (LABA), or a combination of the two, is the mainstay of pharmacological therapy for COPD [6]. However, a significant proportion of patients may not achieve adequate disease control with monotherapy alone [7]. A recent claims-linked survey study of a US population of patients with COPD receiving LAMA monotherapy found that $71.6 \%$ remained symptomatic based on $\geq 2$ COPD-related patient-reported burden of illness measures. For these patients, escalation to LAMA/LABA combination therapy is recommended, with escalation to triple therapy (a combination of a LAMA, LABA, and inhaled corticosteroids [8]) if symptoms persist or if patients are at high risk for a COPD exacerbation [6].

In order to obtain reliable and valid information on the symptom burden of COPD, a comprehensive assessment of symptoms is needed [6]. The use of the modified Medical Research Council (mMRC) dyspnea scale and the COPD assessment test (CAT) are recommended patient-reported outcome (PRO) measures of symptom burden in the 2019 global initiative for chronic obstructive lung disease (GOLD) report [6]. The mMRC dyspnea scale is used to assess breathlessness in patients with COPD and has been demonstrated to correlate well with other measures of health status $[6,9]$.

The CAT has been demonstrated to be a simple and reliable measure of overall COPDrelated health status, and aims to enhance physician-patient communication by promoting concordance between the physician and patient in terms of perception of the severity and impact of the patient's disease. The CAT is an eight-item validated questionnaire that measures the most salient symptoms of COPD, including cough, chest tightness, breathlessness, and activity limitation attributed to COPD symptoms [10]. The CAT total score indicates the symptom burden experienced by the patient; the total score ranges from 0 to 40 , with higher scores $(\geq 10)$ indicating a higher level of symptom burden than lower scores (0-9). While the GOLD strategic document provides direction on assessing symptoms and risk for patients with COPD, it is possible that other patient characteristics may provide further information and assist in predicting increased symptom burden for patients receiving inhaled therapy [6].

The objective of this multivariable analysis of a previously reported claims-linked, crosssectional survey study [11] was to determine demographic, sociodemographic, and clinical characteristics that are predictors of higher symptom burden (as measured by the CAT), in an insured US population of patients with COPD receiving treatment with LAMA monotherapy.

\section{METHODS}

\section{Study Design}

The study was a multivariable analysis of a previously reported claims-linked, cross-sectional survey of patients with COPD who were enrolled in commercial or Medicare Advantage (MA) insurance plans and prescribed LAMA 
monotherapy (study 205862 [HO-16-16642]) [11]. Medical and pharmacy claims and enrollment data from the Optum Research Database (ORD) were used to identify patients between October 1, 2015 and September 30, 2016. The ORD is a large, geographically diverse, US administrative claims database. In 2016, approximately 32.8 million individuals with commercial coverage and 3.2 million individuals with MA coverage were included in the ORD.

Patients who met the study inclusion criteria were recruited directly by mail, consented to the study, and returned a completed paper survey and/or 7-day daily diary. Survey data were collected using a modified Dillman method over 9 weeks from October to December 2016 [12]. Following return of the survey and/or diary, patients were paid $\$ 25$, up to a maximum of $\$ 50$ per patient. Prior to data collection, the study was approved by the New England Institutional Review Board (NEIRB \#120160900; September 9,2016$)$. The study was conducted in accordance with the ethical standards of the institutional and/or national research committee and with the 1964 Helsinki Declaration and its later amendments or comparable ethical standards.

\section{Patient Identification}

Eligible patients were at least 40 years of age with $\geq 2$ medical claims with COPD diagnosis codes (International Classification of Disease10th Revision-Clinical Modification [ICD-10$\mathrm{CM}$ ] J40-J44 codes) in any position at least 30 days apart during the 12-month baseline period [11]. Participants were also required to be continuously enrolled in a commercial or MA health plan with both medical and pharmacy benefits during the baseline period and to have $\geq 2$ pharmacy claims for a LAMA monotherapy in the most recent 6 months of the baseline period [11]. Patients were excluded if they had evidence of prior use of any ICS- or LABA-containing therapy (ICS, ICS/LABA, and LAMA/LABA) during the baseline period. Patients with evidence of diagnosis or treatment for lung cancer during the baseline period were excluded. To be included in this analysis, patients needed to self-report a physician diagnosis of COPD and current use of LAMA monotherapy, and were able to complete the study surveys in English.

\section{Outcome Measures}

Demographic, sociodemographic, and clinical characteristics were collected from patient-reported survey data and baseline claims data. Patient-reported symptom burden was measured using the CAT. Other PRO measures were also collected (mMRC, exacerbations of chronic pulmonary disease tool [EXACT], and medical outcomes short form health survey, 12 items, version 2 [SF-12v2]). COPD-related healthcare resource utilization (HCRU; assessed from the baseline period) was assessed from medical claims. HCRU was defined as COPD-related if the medical claim included an ICD-10-CM diagnosis code for COPD in any position.

\section{Statistical Analysis}

Patients who met all study inclusion and exclusion criteria and had complete, evaluable survey and diary data made up the analysis population. Statistical analyses were performed using SAS software (SAS Institute Inc., Cary, NC, USA, version 9.4) on a Unix platform. All study variables were analyzed descriptively. Dichotomous and polychotomous variables were presented as $n(\%)$ and continuous variables were presented as means, standard deviation (SD), and percentiles. Response rates were calculated and presented according to American Association for Public Opinion Research (AAPOR) Response Rate \#4 recommendations [13].

Multivariable analysis using generalized linear regression modeling with normal distribution and identity link was conducted in order to assess the association between symptom burden and patient baseline characteristics. The dependent variable, CAT total score, was modeled as a continuous variable. The estimated impact on the CAT total score was assessed using patient-reported covariates (age, sex, marital status, educational attainment, urban/ rural residence, smoking status, body mass 
index, and COPD diagnosis duration), and claims-based covariates (baseline Quan-Charlson comorbidity score [14], baseline depression, count of baseline COPD-related office visits [among patients with at least one office visit], and count of baseline COPD exacerbations). COPD exacerbations were defined as qualifying COPD hospitalization events, COPD ED events (with an antibiotic or oral corticosteroid prescription), or COPD ambulatory events (with an antibiotic or oral corticosteroid prescription). Covariates were selected based on descriptive results and clinical significance. Goodness of fit and multicollinearity statistics were assessed during the analysis, and no variables were removed due to endogeneity. Select demographic claims data supplemented missing selfreported information when possible in order to maintain sample size, and this applied to sex and age for three cases. In all analyses, a $P$ value of $<0.05$ was considered statistically significant. Variables were assessed on correlation with increasing or decreasing CAT scores, and were determined to be significant factors if they increased or decreased CAT scores $\geq 2$ points, which has been determined to be the minimal difference that patients deem to be relevant.

\section{RESULTS}

\section{Study Population}

As previously described, 2275 patients met the eligibility criteria and were invited to participate in the study, of whom 528 completed the survey. The response rate was $29.8 \%$; [13] the final evaluable sample included 433 patients on LAMA monotherapy with matched claims, survey, and diary data [11]. Patient demographic, sociodemographic, and clinical characteristics are presented in Table 1 . The majority of patients $(370 / 433 ; 85.5 \%)$ had a CAT total score $\geq 10$ (high CAT impact subgroup), with $169 / 433$ (39.0\%) having a score $\geq 21 ; 63 / 433$ (14.5\%) patients had a CAT score 0-9 (low CAT impact subgroup). The majority of patients were female (total 259/433, 59.8\%; low CAT subgroup 28/63, 44.4\%; high CAT subgroup $231 / 370,62.4 \%$ ) and were either current or former smokers (total 401/433, 92.6\%; low CAT subgroup 56/63, 88.9\%; high CAT subgroup 345/370, 93.2\%). At baseline, mean (SD) QuanCharlson score was 2.4 (1.8) in the low CAT subgroup and 2.2 (1.6) in the high CAT subgroup. During the 12-month baseline period, $13 / 63$ (20.6\%) patients in the low CAT subgroup and $141 / 370(38.1 \%)$ patients in the high CAT subgroup had evidence of diagnosis and/or treatment for depression. COPD had an impact on the well-being of most patients as measured by the CAT. A high correlation was observed between the CAT and other PRO measures (Supplementary Table 1).

\section{Prediction of COPD Symptom Burden}

The strongest predictors of an increase in CAT total score were being diagnosed with COPD for greater than 5 years $(2.25$ points, $P=0.003)$ and being a current smoker (2.22 points, $P=0.025)$ (Table 2). These two factors were related to a clinically meaningful increase in CAT scores. Other statistically significant predictors of increased COPD symptom burden included living in a rural location (increase of 1.99 points, $P=0.044$ ), baseline count of COPD exacerbations (increase of 0.87 points, $P=0.006)$ and count of COPD-related office visits among patients with at least one office visit (increase of 0.43 points, $P=0.016$ ). However, these increases did not reach a clinically meaningful increase of at least 2 points [15].

Descriptive results indicated a statistically significant negative association between age and diagnosis of and/or treatment for depression; that is, depression tended to be less prevalent as age increased. An interaction term between age and depression was created to adjust for this correlation, with age centered at 70 years. The strength and statistical significance of covariates in the model with and without the interaction term were similar; all covariates that were statistically significant in the original model remained statistically significant when the age $x$ depression interaction was included. The interaction of age and depression was a significant predictor of CAT total score (interaction term: $-0.31, P<0.001$, 
Table 1 Demographic, sociodemographic, and clinical characteristics

\begin{tabular}{|c|c|c|c|}
\hline & $\begin{array}{l}\text { Total } \\
(N=433)\end{array}$ & $\begin{array}{l}\text { Low CAT impact }(0-9) \\
(n=63)\end{array}$ & $\begin{array}{l}\text { High CAT impact } \\
(10-40) \\
(n=370)\end{array}$ \\
\hline Age $^{\mathrm{a}}$, mean $(\mathrm{SD})$ & $71.0(9.4)$ & $73.8(7.0)$ & $70.5(9.7)$ \\
\hline Female $^{\mathrm{a}}, n(\%)$ & $259(59.8)$ & $28(44.4)$ & $231(62.4)$ \\
\hline $\mathrm{BMI}^{\mathrm{a}}, \mathrm{kg} / \mathrm{m}^{2}$, mean $(\mathrm{SD})$ & $27.9(7.3)$ & $27.5(5.0)$ & $28.0(7.6)$ \\
\hline \multicolumn{4}{|l|}{ Marital status $^{a}, n(\%)$} \\
\hline Married or living with a partner & $193(44.6)$ & $38(60.3)$ & $155(41.9)$ \\
\hline $\begin{array}{l}\text { Single, never married, separated, } \\
\text { divorced, and/or widowed }\end{array}$ & $240(55.4)$ & $25(39.7)$ & $215(58.1)$ \\
\hline \multicolumn{4}{|l|}{ Education level $^{\mathrm{a}}, n(\%)$} \\
\hline High school or equivalent & $247(58.4)$ & $34(55.7)$ & $213(58.8)$ \\
\hline College/graduate school & $176(41.6)$ & $27(44.3)$ & $149(41.2)$ \\
\hline \multicolumn{4}{|l|}{ Urban/rural residence ${ }^{a}, n(\%)$} \\
\hline Urban/city & $149(34.7)$ & $28(44.4)$ & $121(33.0)$ \\
\hline Suburban & $151(35.1)$ & $23(36.5)$ & $128(34.9)$ \\
\hline Rural & $130(30.2)$ & $12(19.1)$ & $118(32.2)$ \\
\hline \multicolumn{4}{|l|}{ Smoking status ${ }^{\mathrm{a}}, n(\%)$} \\
\hline Current smoker & $122(28.2)$ & $9(14.3)$ & $113(30.5)$ \\
\hline Former smoker & $279(64.4)$ & $47(74.6)$ & $232(62.7)$ \\
\hline Never smoked/lives with smoker & $15(3.5)$ & $2(3.2)$ & $13(3.5)$ \\
\hline Never smoked/no household smoke & $17(3.9)$ & $5(7.9)$ & $12(3.2)$ \\
\hline \multicolumn{4}{|l|}{ Time since COPD diagnosis ${ }^{\mathrm{a}}, n(\%)$} \\
\hline$\leq 5$ Years & $226(52.4)$ & $36(57.1)$ & $190(51.6)$ \\
\hline$>5$ Years & $205(47.6)$ & $27(42.9)$ & $178(48.4)$ \\
\hline Quan-Charlson Comorbidity Score', mean (SD) & $2.2(1.6)$ & $2.4(1.8)$ & $2.2(1.6)$ \\
\hline COPD-related office visits, ${ }^{\mathrm{b}, \mathrm{c}}$, mean (SD) & $3.7(2.3)$ & $3.2(1.8)$ & $3.7(2.4)$ \\
\hline COPD exacerbations ${ }^{\mathrm{b}, \mathrm{d}}$, mean $(\mathrm{SD})$ & $1.9(1.2)$ & $1.6(0.8)$ & $2.0(1.3)$ \\
\hline Baseline depression $^{\mathrm{b}, \mathrm{e}}, n(\%)$ & $154(35.6)$ & $13(20.6)$ & $141(38.1)$ \\
\hline
\end{tabular}

Percentages were calculated based on respondents with available data except for missing values which were expressed as a percentage of the enrolled population $(N=433)$

$B M I$ body mass index, $C A T$ COPD assessment test, COPD chronic obstructive pulmonary disease, $E D$ emergency department, $S D$ standard deviation

a Survey-based

b Claim-based

c Patients with at least one office visit

d Patients with at least one COPD exacerbation, defined as a qualifying COPD hospitalization event, COPD ED event or COPD ambulatory event (with an antibiotic or oral corticosteroid prescription)

${ }^{\mathrm{e}}$ Evidence of depression was assessed using both treatment and diagnosis codes from medical and pharmacy claims; diagnosis of and/or treatment for depression 
Table 2 Generalized linear regression model for predictors of increased CAT total score

\begin{tabular}{|c|c|c|c|c|c|}
\hline \multirow[t]{2}{*}{ Independent variable } & \multicolumn{5}{|c|}{ Dependent variable-CAT total score } \\
\hline & Estimate & SE & Lower 95\% CI & Upper 95\% CI & $\overline{P \text { value }}$ \\
\hline Intercept & 12.23 & 2.20 & 7.92 & 16.54 & $<0.001$ \\
\hline \multicolumn{6}{|l|}{ Demographic/sociodemographic factors } \\
\hline Age (years) - survey-based $^{\mathrm{a}}-$ centered $^{\mathrm{b}}$ & -0.04 & 0.06 & -0.16 & 0.07 & 0.449 \\
\hline \multicolumn{6}{|l|}{ Sex-survey-based ${ }^{\mathrm{a}}$ (ref. female) } \\
\hline Male & -0.34 & 0.84 & -1.99 & 1.30 & 0.681 \\
\hline \multicolumn{6}{|l|}{ Marital status (ref. married or living with a partner) } \\
\hline Single, never married, separated, divorced, and/or widowed & 0.65 & 0.82 & -0.96 & 2.26 & 0.428 \\
\hline \multicolumn{6}{|c|}{ Highest level of education completed (ref. college/graduate school) } \\
\hline High school or equivalent & 0.23 & 0.78 & -1.31 & 1.76 & 0.774 \\
\hline \multicolumn{6}{|l|}{ Urban/rural residence (ref. suburban) } \\
\hline Urban/city & -0.18 & 0.90 & -1.95 & 1.58 & 0.838 \\
\hline Rural & 1.99 & 0.99 & 0.05 & 3.92 & 0.044 \\
\hline \multicolumn{6}{|l|}{ Smoking status (ref. former smoker) } \\
\hline Current smoker & 2.22 & 0.99 & 0.27 & 4.16 & 0.025 \\
\hline Never smoked ${ }^{\mathrm{c}}$ & 2.05 & 1.48 & -0.86 & 4.96 & 0.166 \\
\hline \multicolumn{6}{|l|}{ Clinical characteristics } \\
\hline BMI & 0.01 & 0.06 & -0.10 & 0.13 & 0.834 \\
\hline \multicolumn{6}{|l|}{ Time since COPD diagnosis (ref. $\leq 5$ years) } \\
\hline$>5$ years & 2.25 & 0.77 & 0.74 & 3.76 & 0.003 \\
\hline Baseline $^{\mathrm{d}}$ Quan-Charlson comorbidity score & -0.44 & 0.26 & -0.94 & 0.06 & 0.087 \\
\hline Number of COPD-related office visits ${ }^{\mathrm{e}}$ & 0.43 & 0.18 & 0.08 & 0.78 & 0.016 \\
\hline Count of baseline ${ }^{\mathrm{d}}$ COPD exacerbations (any) & 0.87 & 0.32 & 0.25 & 1.49 & 0.006 \\
\hline Depression $^{\mathrm{f}}$ (ref. no depression) & 2.97 & 0.86 & 1.29 & 4.65 & $<0.001$ \\
\hline
\end{tabular}


Table 2 continued

\begin{tabular}{llllll}
\hline Independent variable & \multicolumn{4}{c}{ Dependent variable-CAT total score } \\
\cline { 2 - 5 } & Estimate & SE & Lower 95\% CI & Upper 95\% CI & $\boldsymbol{P}$ value \\
\hline Age $^{\mathrm{a}, \mathrm{b}} x$ depression $^{\mathrm{f}}{ }^{\text {interaction }}$ & -0.31 & 0.08 & -0.47 & -0.14 & $<\mathbf{0 . 0 0 1}$ \\
\hline
\end{tabular}

Observations read $=387$, observations used $=370$

Generalized linear regression model, normal distribution with identity link

Pearson Chi-square $=19549.41, \mathrm{DF}=354$. Park test: estimate $=-5.93$

Only data for patients with a complete data set were included in the model

Where no reference category is specified, the variable was treated as continuous

Significant $P$ values $(<0.05)$ are indicated in bold font

$B M I$ body mass index, $C I$ confidence interval, $C O P D$ chronic obstructive pulmonary disease, $S E$ standard error

a Patient-reported age was missing for 2 patients, while patient-reported gender was missing for 1 patient; age and gender were ascertained for these patients using their claims enrollment records

b Patient-reported age was centered at 70 years

c Never smoking category included those that live with someone who smokes

d 12 months immediately prior to the survey sample identification

e Medical claims with a primary diagnosis of COPD, among patients with at least one office visit

$\mathrm{f}$ Baseline claims-based diagnosis of and/or treatment for depression

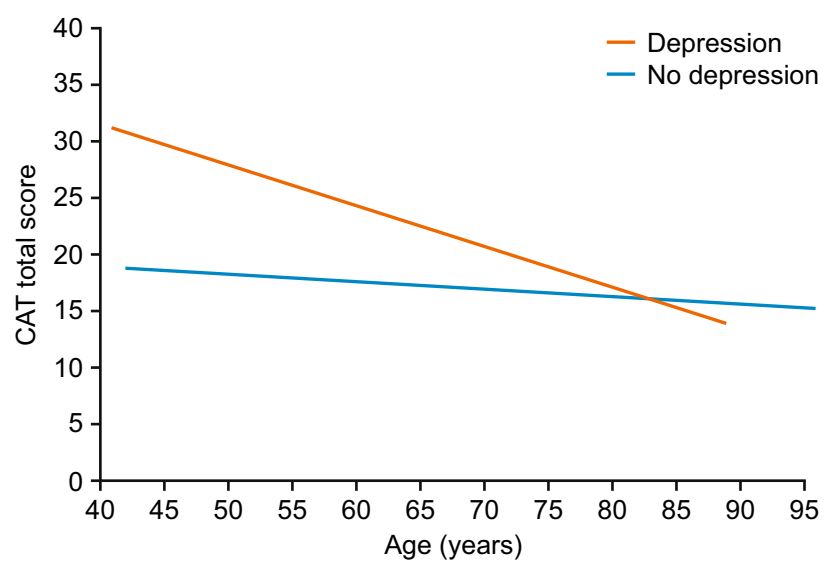

Fig. 1 CAT total score by age, stratified by baseline claims-based diagnosis of and/or treatment for depression. Linear trend lines are based on scatterplots of CAT score

Table 2). CAT score had an inverse relationship with age among patients with depression, with older patients with depression having a lower CAT score than younger patients with depression. In contrast, the association between age and patient-reported symptom burden was not significant in those with no depression, indicating that presence of depression was related to the higher symptom burden and not related to age (Fig. 1). $x$ age among study population. CAT COPD assessment test, $C O P D$ chronic obstructive pulmonary disease

\section{DISCUSSION}

In this multivariable analysis of a claims-linked survey study assessing symptom burden in patients with COPD receiving LAMA monotherapy, multiple patient-level factors that can influence symptom burden, as measured by CAT, were identified. In particular, patients with a long history of COPD diagnosis and who are current smokers were predicted to 
have a higher symptom burden as shown by an increase in CAT score of $\geq 2$ points, which is the estimated minimal clinically important difference (MCID) [15]. This may be a reflection of disease progression and/or indicate that these patients may benefit from additional therapeutic intervention. It is interesting to note that baseline exacerbation counts were highly significant predictors of symptom burden; the effect did not meet the MCID threshold of $\geq 2$ points. This may be due to factors that were not observed in this study, such as the time between the last exacerbation and patient survey. Similarly, other clinical or patient-level factors not assessed in this study may mediate the relationship between exacerbations and symptom burden. Other observational research has shown a stronger relationship between symptom burden and exacerbation rate [16], suggesting this is an important area for further research. Depression is an important comorbidity in patients with COPD and can have negative effects on mortality, rate of COPD exacerbation, length of hospital stay, quality of life (QoL), and functional status [17]. In this study, diagnosis of and/or treatment for depression was related to increased symptom burden when interacted with age (although it did not meet the estimated MCID of a CAT score $\geq 2$ points). This association between CAT score and depression is consistent with previous studies [18], including prior evidence that suggests that age and high levels of symptoms are independent predictors of depression in patients with COPD, and are associated with a lower patient-reported health status [19].

The role of validated PROs in assessment of COPD has become increasingly important due to growing recognition of their value in reflecting the symptom burden and health status of individual patients $[9,20]$. The mMRC dyspnea scale is a valid and reliable measure of breathlessness, relates well to other measures of health status, and can be predictive of mortality risk [6, 9, 21-23]. However, a more comprehensive assessment of symptoms, that goes beyond breathlessness, is now recommended [6]. The St George's Respiratory Questionnaire (SGRQ) is the most widely documented tool for assessment for health status in COPD; however, with 50 questionnaire items, it is often considered to be too complex and burdensome for use in routine clinical practice $[6,20]$. The CAT was developed as a more focused measure of symptom burden in COPD for routine clinical use; consisting of eight items, it is shorter and simpler to use than the SGRQ while providing a broader measure of symptom burden than the mMRC $[10,20,24,25]$. The CAT has been found to be a reliable, appropriate, and responsive instrument for measuring symptom burden in patients with COPD $[6,10,24,26,27]$, and has demonstrated good correlation with established QoL questionnaires, including the SGRQ, and other relevant measures of disease severity $[28,29]$. This is consistent with published data, where a high level of correlation between measures of COPD symptom burden was noted, with $>70 \%$ of patients obtaining high scores on at least two PROs (Supplementary Table 1) [11].

The CAT can be used at a single point in time, is easy to use in clinical practice, and can improve patient-physician communication during routine clinical visits. In real-world studies, the CAT has demonstrated predictive value for future incidence of exacerbations [30] and all-cause mortality [31]. It is responsive to changes in health status following acute exacerbations or pulmonary rehabilitation [32], and it correlates with lung function impairment, exacerbation rates and number of comorbidities [33]. The development and use of the CAT in clinical trials, and continued use in real-world assessments, will ensure that key COPD concepts are reliably measured and that relevant treatment effects are being captured [20].

Standard of care for patients with COPD should include measures of symptom burden, such as the CAT, to evaluate patient outcomes [34]. Physicians should consider the use of instruments such as the CAT on a continuous basis as it has been shown to be responsive to recovery from an exacerbation [32], and to predict treatment failure [35]. It is important, however, for physicians to be aware of factors that may influence the CAT score both at diagnosis and on a continual basis [36]. As demonstrated in this study, factors such as time since COPD diagnosis, smoking status, rural versus 
urban location of residence, baseline counts of exacerbations, and number of office visits are important predictors of symptom burden as indicated by the observed increase in CAT score. The use of the CAT in this way may allow COPD treatment to be better targeted and patient management to be optimized, as well as potentially contributing to the amelioration of both the clinical and economic burden associated with COPD.

Claims-linked survey studies are associated with a number of limitations. The presence of a diagnosis code on a medical claim does not indicate conclusive evidence of the disease, as the diagnosis code may have been incorrectly coded or included as a rule-out criterion. Patients with a diagnosis of asthma were not excluded from the study and spirometry data were not available to confirm the COPD diagnoses. However, to help address these limitations, multiple pharmacy claims and diagnosis codes were required for inclusion. The study is also subject to limitations of survey data, including sampling, coverage, and measurement error. For example, treatment adherence was not measured in this study and the database does not provide information on whether a prescription was redeemed, which may have impacted outcomes. However, it is unlikely that this population has different patterns of adherence than other insured patient populations with COPD [37]. Finally, the study population was made up of patients with commercial health plan coverage and MA enrollees, and therefore the results of the study may not be reflective of uninsured populations, younger patients with COPD, or generalizable to populations outside the United States. For instance, the mean age of patients and proportion of females in our study was higher than typically reported for COPD populations [38], and the level of education was fairly low.

\section{CONCLUSIONS}

The results of this study demonstrate that there are multiple patient-level factors that can potentially influence symptom burden in patients with COPD receiving LAMA monotherapy, as measured by the CAT. Physicians should consider using tools/instruments such as the CAT to measure symptom impact as part of routine care for patients with COPD.

\section{ACKNOWLEDGEMENTS}

The authors thank the participants of this study.

Funding. This study was funded by GlaxoSmithKline (GSK study number 205862 [HO-16-16642]). The funders of the study had a role in the study design, data analysis, data interpretation, and writing of the report. The article-processing charges associated with this publication were funded by GSK. The study was conducted by Optum and funded by GSK. Employees of Optum were not paid for manuscript development.

Medical Writing, Editorial, and Other Assistance. Editorial support (in the form of writing assistance, assembling tables and figures, collating author comments, grammatical editing and referencing) was provided by Elizabeth Jameson, PhD, and Hayley Mukherjee, $\mathrm{PhD}$, at Fishawack Indicia Ltd, UK, and was funded by GSK.

Authorship. All named authors meet the International Committee of Medical Journal Editors (ICMJE) criteria for authorship for this article, take responsibility for the integrity of the work, contributed to the writing and reviewing of the manuscript, and have given final approval for the version to be published. All authors had full access to the data in this study and take complete responsibility for the integrity of the data and accuracy of the data analysis. The corresponding author had the final responsibility to submit for publication and is the guarantor.

Authorship Contributions. BH was involved in the conception/design of the study and analysis/interpretation of data. RHS was involved in the conception/design of the study 
and analysis/interpretation of data. AGH was involved in the conception/design of the study, acquisition of data and analysis/interpretation of data. JW was involved in the conception/ design of the study, acquisition of data and analysis/interpretation of data. BE was involved in the acquisition of data. RR was involved in the conception/design of the study and analysis/interpretation of data.

Disclosures. Riju Ray is an employee of GSK and holds stocks/shares in GSK. Beth Hahn is an employee of GSK and holds stocks/shares in GSK. Richard H. Stanford is an employee of GSK and holds stocks/shares in GSK. Alyssa Goolsby Hunter is an employee of Optum, which was contracted by GSK to conduct the study. Alyssa Goolsby Hunter holds stocks/shares in Optum's parent company, UnitedHealth Group (UNH). Breanna Essoi is an employee of Optum, which was contracted by GSK to conduct the study. John White is an employee of Optum, which was contracted by GSK to conduct the study. Employees of Optum were not paid for manuscript development.

Compliance with Ethics Guidelines. Prior to data collection, the study was approved by the New England Institutional Review Board (NEIRB \#120160900; September 9, 2016). The study was conducted in accordance with the ethical standards of the institutional and/or national research committee and with the 1964 Helsinki Declaration and its later amendments or comparable ethical standards.

Data Availability. This study was a collaboration between GSK and Optum. GSK makes available anonymized individual participant data and associated documents from interventional clinical studies which evaluate medicines, upon approval of proposals submitted to www.clinicalstudydatarequest.com. To access data for other types of GSK sponsored research, for study documents without patient-level data and for clinical studies not listed, please submit an enquiry via the website. The datasets analyzed during the current study are not publicly available. For this manuscript, the data are contained in a database owned by Optum and contains proprietary elements and therefore cannot be broadly disclosed or made publicly available at this time. The disclosure of this data to third-party clients assumes certain data security and privacy protocols are in place and that the third-party client has executed Optum's standard license agreement which includes restrictive covenants governing the use of the data.

Open Access. This article is distributed under the terms of the Creative Commons Attribution-NonCommercial 4.0 International License (http://creativecommons.org/licenses/ by-nc/4.0/), which permits any noncommercial use, distribution, and reproduction in any medium, provided you give appropriate credit to the original author(s) and the source, provide a link to the Creative Commons license, and indicate if changes were made.

\section{REFERENCES}

1. Ehteshami-Afshar S, FitzGerald JM, Doyle-Waters MM, Sadatsafavi M. The global economic burden of asthma and chronic obstructive pulmonary disease. Int J Tuberc Lung Dis. 2016;20:11-23. https://doi. org/10.5588/ijtld.15.0472.

2. Wheaton A, Cunningham T, Ford E, Croft J. Employment and activity limitations among adults with chronic obstructive pulmonary disease-United States, 2013. Morb Mortal Wkly Rep. 2015;64:289-95.

3. Lopez-Campos JL, Tan W, Soriano JB. Global burden of COPD. Respirol. 2016;21:14-23. https://doi. org/10.1111/resp.12660.

4. Miravitlles M, et al. Observational study to characterise 24-hour COPD symptoms and their relationship with patient-reported outcomes: results from the ASSESS study. Respir Res. 2014;15:122. https:// doi.org/10.1186/s12931-014-0122-1.

5. Kessler R, et al. Symptom variability in patients with severe COPD: a pan-European cross-sectional study. Eur Respir J. 2011;37:264-72. https://doi.org/ 10.1183/09031936.00051110.

6. Global Initiative for Chronic Obstructive Lung Disease (GOLD). Global strategy for the diagnosis, management and prevention of chronic obstructive pulmonary disease. (2019). 
7. Dransfield MT, et al. Disease severity and symptoms among patients receiving monotherapy for COPD. Prim Care Respir J. 2011;20:46-53. https://doi.org/ 10.4104/pcrj.2010.00059.

8. National Center for Health Statistics. Health, United States, 2016, https://www.cdc.gov/nchs/hus/ index.htm (2016).

9. Cazzola $\mathrm{M}$, et al. A review of the most common patient-reported outcomes in COPD-revisiting current knowledge and estimating future challenges. Int $\mathrm{J}$ Chronic Obstr Pulm Dis. 2015;10:725-38. https://doi.org/10.2147/COPD. S77368.

10. Karloh M, et al. The COPD assessment test: what do we know so far? A systematic review and metaanalysis about clinical outcomes prediction and classification of patients into GOLD stages. Chest. 2016;149:413-25. https://doi.org/10.1378/chest.151752 .

11. Hahn B, et al. Patient-reported burden of illness in a prevalent COPD population treated with long-acting muscarinic antagonist monotherapy: a claimslinked patient survey study. Pulm Ther. 2019;5:69-80. https://doi.org/10.1007/s41030-0190091-0.

12. Dillman, D., Smyth, J., Christian, L. Internet, mail, and mixed-mode surveys. The Tailored Design Method. 4th ed. New Jersey, United States: Wiley (2014).

13. The American Association for Public Opinion Research. Standard Definitions: Final Dispositions of Case Codes and Outcome Rates for Surveys.https://www.aapor.org/AAPOR_Main/media/ MainSiteFiles/Standard-Definitions2015_8thEd.pdf (2015).

14. Quan H, et al. Updating and validating the Charlson comorbidity index and score for risk adjustment in hospital discharge abstracts using data from 6 countries. Am J Epidemiol. 2011;173:676-82. https://doi.org/10.1093/aje/ kwq433.

15. Kon SS, et al. Minimum clinically important difference for the COPD assessment test: a prospective analysis. Lancet. Respir Med. 2014;2:195-203. https://doi.org/10.1016/s2213-2600(14)70001-3.

16. Miravitlles $M$, et al. The relationship between 24-hour symptoms and COPD exacerbations and healthcare resource use: results from an observational study (ASSESS). COPD. 2016;13:561-8. https://doi.org/10.3109/15412555.2016.1150447.

17. Miravitlles M, Ribera A. Understanding the impact of symptoms on the burden of COPD. Respir Res.
2017;18:67. https://doi.org/10.1186/s12931-0170548-3.

18. Miravitlles $M$, et al. Depressive status explains a significant amount of the variance in COPD assessment test (CAT) scores. Int J of Chronic Obstr Pulm Dis. 2018;13:823-31. https://doi.org/10.2147/ copd.s154791.

19. Cleland JA, Lee AJ, Hall S. Associations of depression and anxiety with gender, age, health-related quality of life and symptoms in primary care COPD patients. Fam Pract. 2007;24:217-23. https://doi. org/10.1093/fampra/cmm009.

20. Jones P, Miravitlles M, van der Molen T, Kulich K. Beyond FEV(1) in COPD: a review of patient-reported outcomes and their measurement. Int J of Chronic Obstr Pulm Dis. 2012;7:697-709. https:// doi.org/10.2147/copd.s32675.

21. Nishimura K, Izumi T, Tsukino M, Oga T. Dyspnea is a better predictor of 5-year survival than airway obstruction in patients with COPD. Chest. 2002;121:1434-40.

22. Bestall JC, et al. Usefulness of the Medical Research Council (MRC) dyspnoea scale as a measure of disability in patients with chronic obstructive pulmonary disease. Thorax. 1999;54:581-6.

23. Mahler DA, et al. Patient-reported dyspnea in COPD reliability and association with stage of disease. Chest. 2009;136:1473-9. https://doi.org/10.1378/ chest.09-0934.

24. Jones PW, et al. Development and first validation of the COPD assessment test. Eur Respir J. 2009;34:648-54. 09031936.00102509 .

25. Huang WC, Wu MF, Chen HC, Hsu JY. Features of COPD patients by comparing CAT with mMRC: a retrospective, cross-sectional study. NPJ Prim Care Respir Med. 2015;25:15063. https://doi.org/10. 1038/npjpcrm.2015.63.

26. Jones PW, Tabberer M, Chen WH. Creating scenarios of the impact of COPD and their relationship to COPD Assessment Test (CAT) scores. BMC Pulm Med. 2011;11:42. https://doi.org/10.1186/14712466-11-42.

27. Lari SM, Attaran D, Tohidi M. Improving communication between the physician and the COPD patient: an evaluation of the utility of the COPD assessment test in primary care. Patient Relat Outcome Meas. 2014;5:145-52. https://doi.org/10. 2147/prom.s54484.

28. Ringbaek T, Martinez G, Lange P. A comparison of the assessment of quality of life with CAT, CCQ, 
and SGRQ in COPD patients participating in pulmonary rehabilitation. COPD. 2012;9:12-5. https:// doi.org/10.3109/15412555.2011.630248.

29. Jones PW, et al. Properties of the COPD assessment test in a cross-sectional European study. Eur Respir J. 2011;38:29-35. https://doi.org/10.1183/ 09031936.00177210 .

30. Lee SD, et al. The COPD assessment test (CAT) assists prediction of COPD exacerbations in highrisk patients. Respir Med. 2014;108:600-8. https:// doi.org/10.1016/j.rmed.2013.12.014.

31. Casanova C, et al. Differential effect of modified Medical Research Council dyspnea, COPD assessment test, and clinical COPD questionnaire for symptoms evaluation within the new GOLD staging and mortality in COPD. Chest. 2015;148:159-68. https://doi.org/10.1378/chest.142449.

32. Jones PW, et al. Tests of the responsiveness of the COPD assessment test following acute exacerbation and pulmonary rehabilitation. Chest. 2012;142:134-40. https://doi.org/10.1378/chest.110309 .

33. Lopez-Campos JL, et al. Evaluation of the COPD Assessment Test and GOLD patient types: a crosssectional analysis. Int J Chronic Obstr Pulm Dis. 2015;10:975-84. https://doi.org/10.2147/COPD. S82781.
34. van der Molen T, Miravitlles M, Kocks JW. COPD management: role of symptom assessment in routine clinical practice. Int J Chronic Obstr Pulm Dis. 2013;8:461-71. https://doi.org/10.2147/copd. s49392.

35. Garcia-Sidro P, et al. The CAT (COPD assessment test) questionnaire as a predictor of the evolution of severe COPD exacerbations. Respir Med. 2015;109:1546-52. https://doi.org/10.1016/j.rmed. 2015.10.011.

36. Miyazaki M, et al. Analysis of comorbid factors that increase the COPD assessment test scores. Respir Res. 2014;15:13. https://doi.org/10.1186/14659921-15-13.

37. Wallace AE, et al. Health care resource utilization and exacerbation rates in patients with COPD stratified by disease severity in a commercially insured population. J Manag Care \& Spec Pharm. 2019;25:205-17. https://doi.org/10.18553/jmcp. 2019.25.2.205.

38. Bogart $\mathrm{M}$, et al. Medication adherence and persistence in chronic obstructive pulmonary disease patients receiving triple therapy in a USA commercially insured population. Int J Chronic Obstr Pulm Dis. 2019;14:343-52. https://doi.org/10.2147/ COPD.S184653. 